\title{
Tensile Studies on Random Oriented Human Hair Fiber Reinforced Polyester Composites
}

\author{
P.Divakara Rao ${ }^{1 *}$, C.Udaya kiran ${ }^{2}$, K.Eshwara Prasad ${ }^{3}$ \\ ${ }^{1}$ Department of Mechanical Engineering, J.B. Institute of Engineering and Technology, \\ Hyderabad, Telangana, India. \\ ${ }^{2}$ Department of Mechanical Engineering, J.B. Institute of Engineering and Technology, \\ Hyderabad, Telangana, India. \\ ${ }^{3}$ Department of Mechanical Engineering, Jawaharlal Nehru Technological University, \\ Hyderabad, Telangana, India. \\ *Corresponding author: raodivakar_p@yahoo.co.in
}

\begin{abstract}
Composite specimens are prepared by impregnating human hair in polyester resin. Randomly oriented chopped Human hair with varied weight ratios and Fiber lengths are used for the present experimental study. The composites are compression moulded using hand layup technique. An attempt is made to find out the influence of fiber weight ratio and length on the Tensile strength and tensile modulus. Optimum Fiber weight ratio and Fiber length are identified for maximizing the tensile strength and tensile modulus of the Human hair polyester composites. Experiments are carried out as per the standards and results are discussed. Further, Tensile stress and Tensile Modulus of the composite at optimum fiber length are estimated using different theoretical models and are compared with the experimental results.
\end{abstract}

Key words: Polyester resin, Human Hair Fiber, Composite, theoretical models.

\section{INTRODUCTION}

Natural Fiber reinforced composites have received much attention nowadays due to their light weight, low cost and eco-friendly nature. In addition, natural fibers offer increased recycling capabilities over conventional polymers ${ }^{1}$. Good amount of research is published on plant based natural fibers but research on animal fiber based composites is meagre. Animal fibers such as Chicken Feather, Human hair, Hairs of other birds and animal are commonly described as a waste by-product and their disposal methods are contributing to environmental pollution ${ }^{2}$. Human hair by nature is a fibrous material with good tensile properties. The primary component of the hair fiber is keratin which consists of proteins and long chain (polymers) of amino acids ${ }^{3}$. Cortex in the hair fiber is primarily responsible for the tensile properties of human hair ${ }^{4}$. Mechanical Properties viz, Tensile strength and Tensile Modulus of fiber reinforced composites are greatly influenced by its Fiber volume fraction as well as fiber length. The maximum values of tensile strength and modulus of the coir fiber reinforced composites is achieved at the $30 \mathrm{~mm}$ fiber length ${ }^{5}$

If these fibers are successfully impregnated into resins to make composites and are used for applications, it offers much more effective solution for environmental pollution issues. Presently human hair composites are being used in the areas of construction, automobiles and moulded furniture ${ }^{6}$. Both human hair and chicken feather are naturally made out of keratin, reports on human hair based composites is relatively less. In the present experimental study, authors made an attempt to make human hair reinforced composite specimens to mechanically characterize the composite material.

\section{HUMAN HAIR FIBER AND ITS PROPERTIES}

Keratin is the primary constituent of Human Hair fiber. These keratins are proteins, polymers of amino acids. Keratin proteins form the cytoskeleton of all epidermal cells. Keratin proteins comprise $65-95 \%$ of the total hair fiber by weight. Mostly hair fibers are made of hard keratins which do not dissolve in water. Hard keratins are highly resistant to proteolytic enzymes. Hair fiber durability and resistance to degradation under environmental stress comes from the linkage between the cystine molecules and keratin proteins that form disulfide chemical bonds. These bonds are very strong. Amino acids with their quantities present in normal hair fiber are shown in figure $1^{7,8}$

The hair is composed of raw elements which are shown in figure 2. Other element that are present in the hair in trace amounts are magnesium, arsenic, iron, chromium and other metals and minerals ${ }^{7,8}$. 


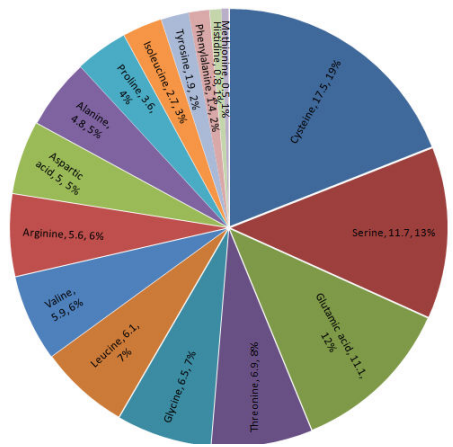

Figure 1. Amino acids present in Human hair

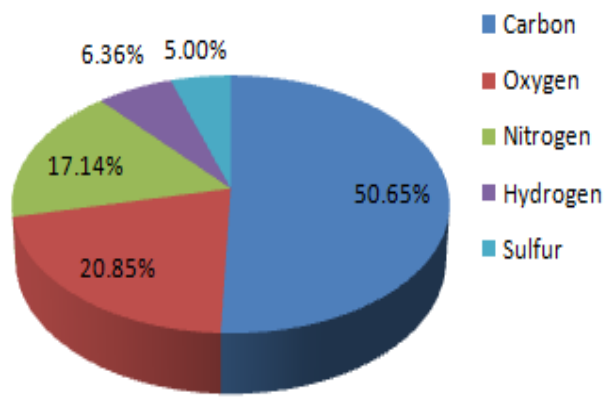

Figure 2. Raw elements contained in the Hair fiber

A typical Hair fiber structure and its cross section are shown in figure 3.

A single hair strand can withstand a load of nearly $70 \mathrm{~g}$. Various properties of normal human hair are shown in table $1^{10}$.

Table 1. Properties of Human Hair fiber

\begin{tabular}{lccc}
\hline $\begin{array}{l}\text { Density } \\
\mathrm{g} / \mathrm{cm}^{3}\end{array}$ & $\begin{array}{c}\text { Tensile } \\
\text { Strength } \\
\mathrm{MPa}\end{array}$ & $\begin{array}{c}\text { Young's } \\
\text { Modulus } \\
\mathrm{GPa}\end{array}$ & $\begin{array}{l}\text { Poisson } \\
\text { 's ratio }\end{array}$ \\
\hline 1.34 & 200 & $1.74-4.39$ & 0.37
\end{tabular}

\section{DISCONTINUOUS AND RANDOMLY} ORIENTED FIBER COMPOSITES

Reinforcement efficiency for discontinuous fibers is lower when compared to continuous fibers. However the usage of discontinuous fibers is predominant in the commercial market. Chopped glass fibers are extensively used in many applications. Short fiber composites can be produced with $90 \%$ of elasticity Modulus and $50 \%$ of tensile strength when compared to continuous fiber composites.

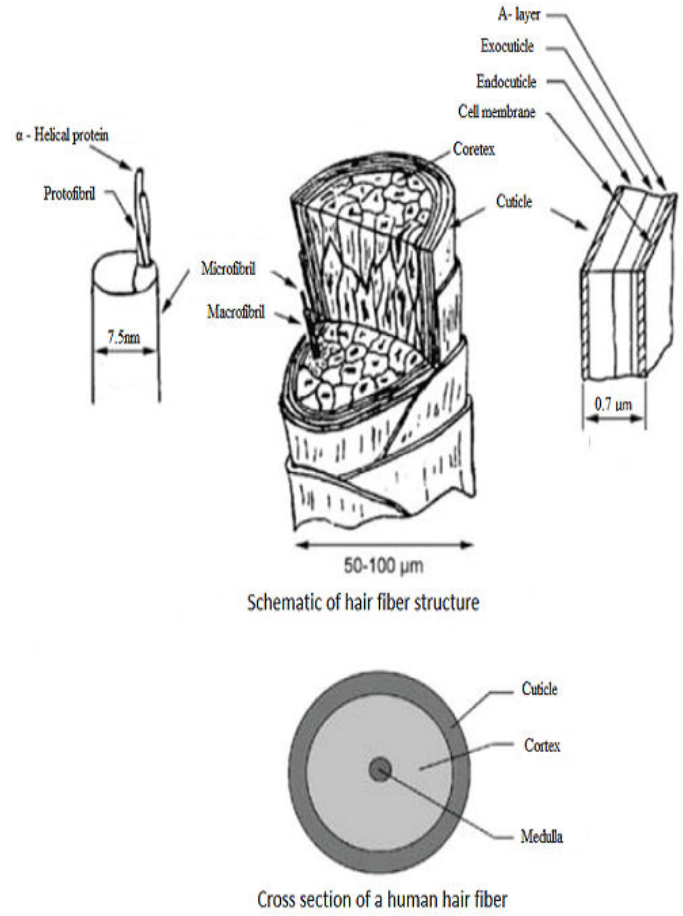

Figure 3: Structure of Hair fiber ${ }^{9}$

\section{Discontinuous and aligned fiber composites}

The longitudinal strength of a discontinuous and aligned fiber composite with uniformly distributed fibers $\left(l>l_{c}\right)$ is given by the relationship (1).

$$
\sigma_{c d}=\sigma_{f} V_{f}\left(1-\frac{l_{c}}{2 l}\right)+\sigma_{m}\left(1-V_{f}\right) \text {--------- (1) }
$$

Where, $\sigma_{f} \sigma_{m}$ are fracture strength of fiber and stress of matrix respectively when the composite fails and $l_{c}$ is the critical length of the fiber. $V_{f}$ represents the Volume fraction of the fibers in the composite.

\section{Discontinuous and randomly oriented fiber Composites}

Normally, short and discontinuous fibers are employed when the fiber orientation is random. Rule of mixtures expression for this kind of composites is given by equation (2)

$$
E_{c d}=K E_{f} V_{f}+E_{m} V_{m}
$$

Where $\mathrm{K}$ is fiber efficiency that depend on fiber volume fraction, $V_{f}$ and $E_{f} / E_{m}$ ratio. The value of $\mathrm{K}$ varies between 0.1 to 0.6 . Thus the modulus of 
elasticity increases with increase in volume fraction of fiber to some portion.

Anisotropy is exhibited by the aligned fibrous composites there by giving maximum strength and reinforcement along the alignment direction, where as fiber reinforcement is nonexistent in the transverse direction leading to low tensile stresses. However, Isotropic mechanical properties are exhibited by the randomly oriented short fiber composites. Applications involving multidirectional stresses normally use randomly oriented discontinuous fibers. The reinforcement efficiency in this case is only one-fifth that of an aligned fiber composite.

Theoretical models for tensile properties of randomly oriented fiber distribution composites Different theories are used to model the mechanical properties of the fiber reinforced composites. Some of them are:

1. Series and Parallel model: Tensile strength and tensile modulus are calculated using the equations 3 to 6 as given by Harjeet S.Jaggi et al. ${ }^{11}$

Series Model

$$
\begin{aligned}
& E_{c}=E_{f} V_{f}+E_{m} V m \\
& \sigma_{c}=\sigma_{f} V_{f}+\sigma_{m} V_{m}
\end{aligned}
$$

Parallel Model

$$
\begin{gathered}
E_{c}=\frac{E_{m} E_{f}}{E_{m} V_{f}+E_{f} V_{m}} \\
\sigma_{c}=\frac{\sigma_{m} \sigma_{f}}{\sigma_{m} V_{f}+\sigma_{f} V_{m}}
\end{gathered}
$$

Where E, $\sigma$ and V are Young's Modulus, Stress and volume fraction respectively. The subscripts $\mathrm{c}$, f and $\mathrm{m}$ denote composite, fiber and matrix respectively

\section{Hirsch's Model:}

This model is the combination of series and parallel model. According to Hirch's model, the stress and young's modulus are given by equations $7 \& 8$.

$$
\begin{aligned}
& E_{c}=x\left(E_{m} V_{m}+E_{f} V_{f}\right)+(1-x) \frac{E_{m} E_{f}}{E_{m} V_{f}+E_{f} V_{m}} \text {----- (7) } \\
& \sigma_{c}=x\left(\sigma_{m} V_{m}+\sigma_{f} V_{f}\right)+(1-x) \frac{\sigma_{m} \sigma_{f}}{\sigma_{m} V_{f}+\sigma_{f} V_{m}} \text {------ (8) }
\end{aligned}
$$

Where ' $\mathrm{x}$ ' is an empherical parameter that characterizes the stress transfer between the matrix and fiber. The value of $\mathrm{x}$ is taken as 0.4 for longitudinally oriented fiber composites and is 0.1 for random oriented fiber composites ${ }^{12}$.
3. Modified Bowyer and Badar's model ${ }^{12}$ :

According to this model, the Tensile modulus and tensile stress are given by equations $9 \& 10$

$$
\begin{aligned}
& E_{c}=E_{f} K_{1} K_{2} V_{f}=E_{m} V_{m} \\
& \sigma_{c}=\sigma_{f} K_{1} K_{2} V_{f}+\sigma_{m} V_{m}
\end{aligned}
$$

Where $\mathrm{K}_{1}$ is fiber orientation factor that varies between 0 to 1 and $K_{2}$ is fiber length factor which is estimated by

$$
\begin{aligned}
K_{2} & =L-\frac{L_{c}}{2 L} \text { for fibers with } \mathrm{L}>\mathrm{L}_{\mathrm{c}} \\
& =\frac{L}{2 L_{c}} \text { for fibers with } \mathrm{L}<\mathrm{L}_{\mathrm{c}}
\end{aligned}
$$

\section{Einstein and Guth Model ${ }^{13}$}

Tensile Modulus and Stress according to this model are given by equations $11 \& 12$

$$
\begin{aligned}
& E_{c}=E_{m}\left(1+2.5 V_{f}+14.1 V_{f}^{2}\right) \\
& \sigma_{c}=\sigma_{m}\left(1-V_{f}^{2 / 3}\right)
\end{aligned}
$$

\section{EXPERIMENTAL}

\section{Materials}

Human hair Fibers obtained from the local agencies were used for the present experimental study. Polyester resin obtained from $\mathrm{M} / \mathrm{s}$. Anand Composites, Hyderabad is used as the matrix material. Methyl Ethyl Ketone Peroxide (MEKP) and Cobalt Naphthenate supplied by M/s. SP Engineering Ltd., Hyderabad, are used as Catalyst and accelerator respectively.

\section{Fiber Treatment}

The Human Hair Fibers obtained are taken in to a plastic tray. A Hair Conditioning Shampoo was added into the tray and the fibers are allowed to soak in the solution for 30 minutes. The fibers are then washed thoroughly with water to remove the excess of shampoo sticking to the Fibers. Final washings were carried out with distilled water and the fibers are then dried in sunlight for 2 hours. Then the fibers are chopped into short fibers of required lengths of 10, 20, 30,40 and $50 \mathrm{~mm}$ for present study.

\section{Preparation of Mould}

Mild Steel material is used to make Mould of 300 $\times 300 \times 3 \mathrm{~mm}$ dimensions, is used to make the composite sheets. Initially, the mould is cleaned with the cleaning agent, to remove any greasy, oily material that is present on the mould surface. The mould becomes ready after it is applied a layer of releasing 
agent, Poly Vinyl Alcohol (PVA) and let it dry for 15 minutes.

\section{Preparation of composite and Test specimen}

Hair Fibers cut into specified length and is uniformly spread in the mould. The polyester resin along with the catalyst and accelerators in required quantities are mixed thoroughly as per the procedure and poured in to the mould to fill it. Sufficient care is taken to have uniform distribution and full impregnation of Fiber in the resin. The mould is then closed with other half part of mould, clamped tightly and is kept for 24 hours at room temperature as polyester cures completely in 24 hours of time. The composite sample sheets are fabricated with different fiber weight ratios.

\section{Specimen Preparation and Testing}

Test specimens are cut from the completely cured composite sheet as per ASTM standards is shown in the figure $4 \mathrm{a}$. The tensile tests are carried out using Autograph AG15, Shimazdu 0-50 kN range with an accuracy of $0.1 \mathrm{~N}$. For each test, 5 specimens are used, and the average value of tensile load at breaking point is calculated for these 5 specimens. A specimen under test is shown in figure $4 b$.

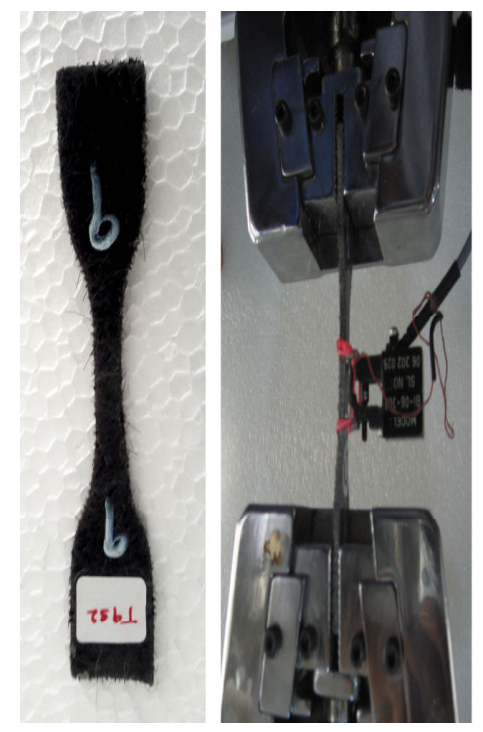

Figure 4. Specimen (a) before (b) during testing

\section{RESULTS AND DISCUSSIONS}

Random oriented Human hair fiber polyester composites have been produced with five different fiber lengths and seven different volume fractions for each fiber length. The density of the composite is observed to be increasing with increasing fiber volume fractions although the density the composite is less than density of fiber and more than the matrix material. Variation of Composite density with weight fraction for optimum length composite is shown in figure 5 .

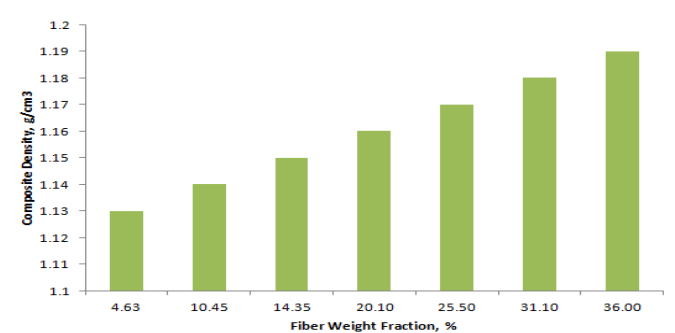

Figure 5. Variation of Composite density with fiber Weight fraction.

\section{Effect of fiber Weight Fraction on the tensile strength.}

Experimental results from the tensile tests for different specimens with varying fiber lengths and fiber weight fraction are presented in Table 2 . It is observed from the table that tensile strength is increasing with increase in Fiber length and Fiber weight ratio.

Few fibers are present for low fiber weight fractions and the stresses in the composite are high enough to break the fibers. The broken fibers do not carry any load and these broken fibers can be regarded as an array of aligned holes. As a result, the tensile strength of the composite falls below that of the matrix material. This phenomenon can be witnessed from figure 6 , where the tensile stress is low at lesser fiber weight fractions. As explained in composite theory ${ }^{14}$, the reinforcing action of the fiber is only effective once the fiber volume fraction exceeds the critical value. Goshal et al. ${ }^{15}$ explained the minimum and critical fiber volume fractions for short banana fiber reinforced vinyl - ester composite and found them as $15 \%$ and $25 \%$ respectively. However there is a maximum fiber content beyond which the properties of the composite deteriote ${ }^{16,17}$. In the present study, the tensile properties of the composite registered a clear decline beyond $20 \%$ fiber weight fraction. This may be due to the impregnation and wettability issues close to these maximum fiber weight fractions. Also at higher fiber weight fractions, fiber to fiber spacing becomes so small that the stress transfer between the fiber and matrix becomes ineffective as explained by $\operatorname{Pan}^{18}$. 
Table 2. Tensile properties of Human Hair Reinforced polyester composite

\begin{tabular}{|c|c|c|}
\hline $\begin{array}{c}\text { Fiber } \\
\text { Length }(\mathrm{mm})\end{array}$ & $\begin{array}{l}\text { Fiber weight } \\
\text { Ratio(\%) }\end{array}$ & $\begin{array}{c}\text { Tensile } \\
\text { Stress(MPa) }\end{array}$ \\
\hline \multirow{7}{*}{10} & 4.74 & 06.30 \\
\hline & 9.3 & 08.70 \\
\hline & 14.7 & 18.00 \\
\hline & 19.5 & 19.40 \\
\hline & 25.1 & 14.50 \\
\hline & 30.6 & 10.78 \\
\hline & 35.43 & 07.00 \\
\hline \multirow{7}{*}{20} & 5.07 & 09.08 \\
\hline & 10.04 & 14.20 \\
\hline & 15.58 & 18.58 \\
\hline & 20.5 & 23.50 \\
\hline & 25.8 & 18.90 \\
\hline & 31.86 & 16.41 \\
\hline & 36.2 & 10.38 \\
\hline \multirow{7}{*}{30} & 4.63 & 12.03 \\
\hline & 10.45 & 19.02 \\
\hline & 14.35 & 23.18 \\
\hline & 20.1 & 31.45 \\
\hline & 25.5 & 26.04 \\
\hline & 31.1 & 21.37 \\
\hline & 36 & 13.72 \\
\hline \multirow{7}{*}{40} & 5.1 & 12.00 \\
\hline & 9.85 & 17.87 \\
\hline & 15.62 & 22.12 \\
\hline & 20.6 & 27.00 \\
\hline & 26.2 & 25.30 \\
\hline & 31.4 & 18.64 \\
\hline & 35.5 & 11.52 \\
\hline \multirow{7}{*}{50} & 4.1 & 11.30 \\
\hline & 9.7 & 16.41 \\
\hline & 14.8 & 21.90 \\
\hline & 20.5 & 24.00 \\
\hline & 24.4 & 22.06 \\
\hline & 29.9 & 18.72 \\
\hline & 36.1 & 09.82 \\
\hline
\end{tabular}

Variation of tensile strength with change in fiber weight ratio is depicted in figure 5. It is evident that tensile strength increases with increase in fiber weight ratio up to $20 \%$ and then decreases with further increment in the fiber loading. This is due to improper impregnation of fibers beyond $20 \%$ fiber loading. Also the higher fiber loading resulted in poor fiber efficiency and hence low $\mathrm{K}$ value, leading to reduction in the tensile strength.

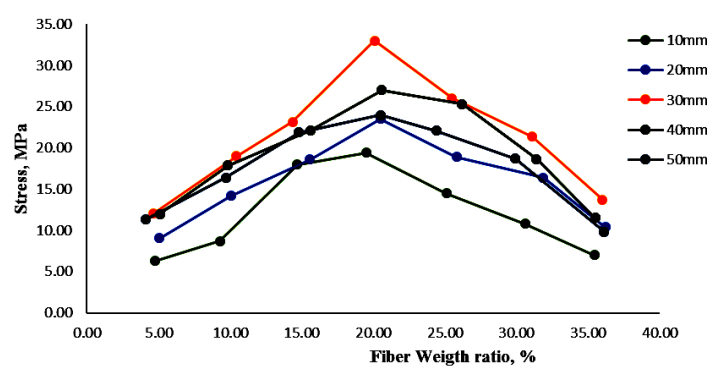

Figure 5. Effect of Fiber weight ratio on Tensile Strength of Human Hair Reinforced Polyester Composites

Variation of Tensile stress for different fiber lengths is plotted in figure 6 . It is clearly evident from figure that the tensile strength of Human Hair Polyester reinforced composites is increasing with increase of fiber length up to $30 \mathrm{~mm}$. Further increase of fiber length has resulted in decreased tensile strength of the composite. This may be due to the fact that discontinuous hair fibers of length more than $30 \mathrm{~mm}$ are not impregnated straight into the matrix and there by failed to carry the required load.

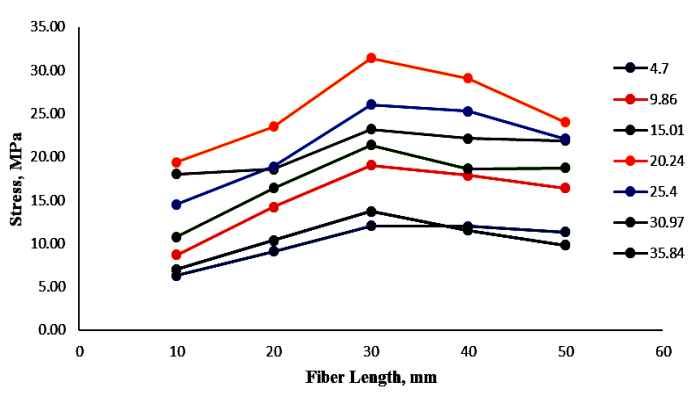

Figure 6. Effect of Fiber length on Tensile Strength of Human Hair Reinforced Polyester Composites

As better tensile strength of composite is observed at $30 \mathrm{~mm}$ fiber length, experiments are further conducted at this fiber length to know the tensile modulus and the results are tabulated in table 3 .

Journal of Mechanical Engineering, Vol. ME 47, December 2017

Transaction of the Mechanical Engineering Division, The Institution of Engineers, Bangladesh 
Table 3. Experimental tensile properties of Human hair composite at optimum fiber length

\begin{tabular}{ccc}
$\begin{array}{c}\text { Fiber weight } \\
\text { Ratio, \% }\end{array}$ & $\begin{array}{c}\text { Tensile } \\
\text { Stress(MPa) }\end{array}$ & $\begin{array}{c}\text { Tensile } \\
\text { Modulus(GPa) }\end{array}$ \\
\hline 4.63 & 12.03 & 3.73 \\
10.45 & 19.02 & 3.82 \\
14.35 & 23.18 & 4.02 \\
20.1 & 31.45 & 4.13 \\
25.5 & 26.04 & 3.89 \\
31.1 & 21.37 & 3.28 \\
36.0 & 13.72 & 1.99 \\
\hline
\end{tabular}

Variation of Tensile Modulus with the fiber weight fraction is shown in figure 7. Fiber void content is calculated using equation 13 and variation of void content with fiber weight ratio at optimum fiber length composite is shown in figure 8 .

$$
V_{\text {void }}=\left(\frac{\rho_{c t h}-\rho_{c e x}}{\rho_{c t h}}\right) X 100
$$

Where, $\rho_{c t h}, \quad \rho_{\text {cex }}$ are theoretical and experimental densities respectively.

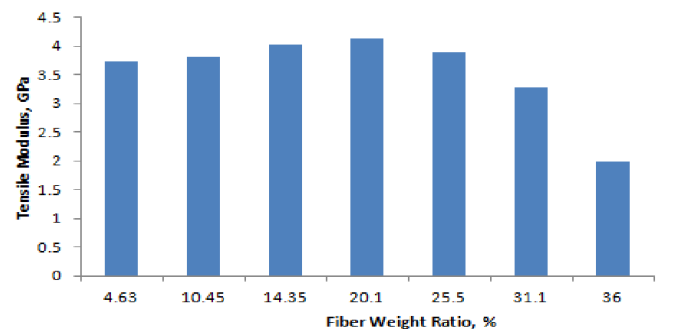

Figure 7. Variation of Tensile Modulus with Fiber Weight Ratio at optimum fiber length

Higher positive void volume content percentage is observed below $15 \%$ and above $25 \%$ fiber weight ratios. This is another reason why the tensile strength is low in these two regions as shown in the figure 5.

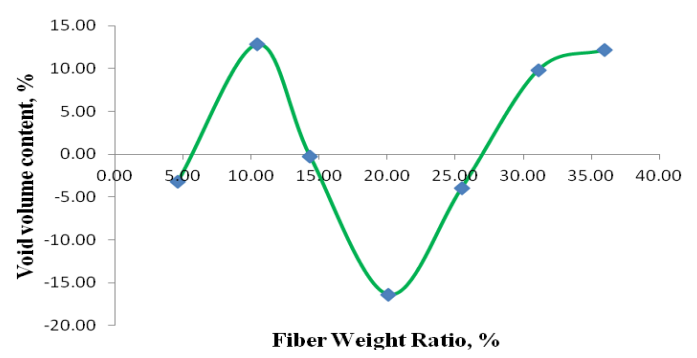

Figure 8. Variation of Void volume content with fiber weight ratio (fiber length $30 \mathrm{~mm}$ )

Different theoretical models as explained through the equations 3 to 12 are used to predict tensile stress and Young's modulus of the composite made of $30 \mathrm{~mm}$ fiber length. The results obtained from these theoretical models are compared with experimental values and are shown in figures 9 and 10 . Though the experimental tensile modulus values are in good agreement with different theatrical models, tensile stress values fall below the stress values predicted by different models.

It is noticed that experimental tensile modulus has dropped sharply at high fiber weight fractions. This is due to the fact that high fiber volume fractions resulted in the formation of voids between the adjacent fibers because of changing resin flow dynamics as suggested by D.U. Shah et al. ${ }^{19}$. It is also observed that the maximum positive void volume content occurred at 10.45 and $36 \%$ fiber weight ratio where low stress values are recorded. Higher void volume percentage is one of the reasons for sudden drop in tensile modulus at $36 \%$ weight ratio. Low fiber efficiency is another important reason for low values of tensile modulus beyond $20 \%$ of fiber loading. 


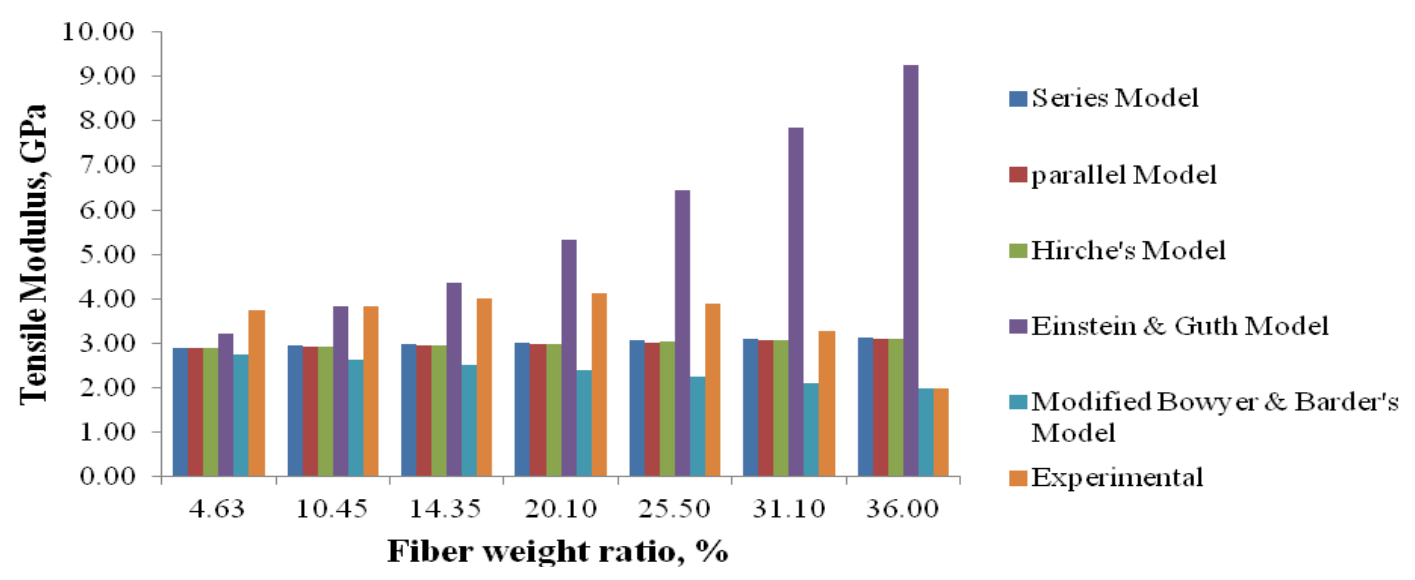

Figure 9. Comparison of composite Tensile Modulus among different models

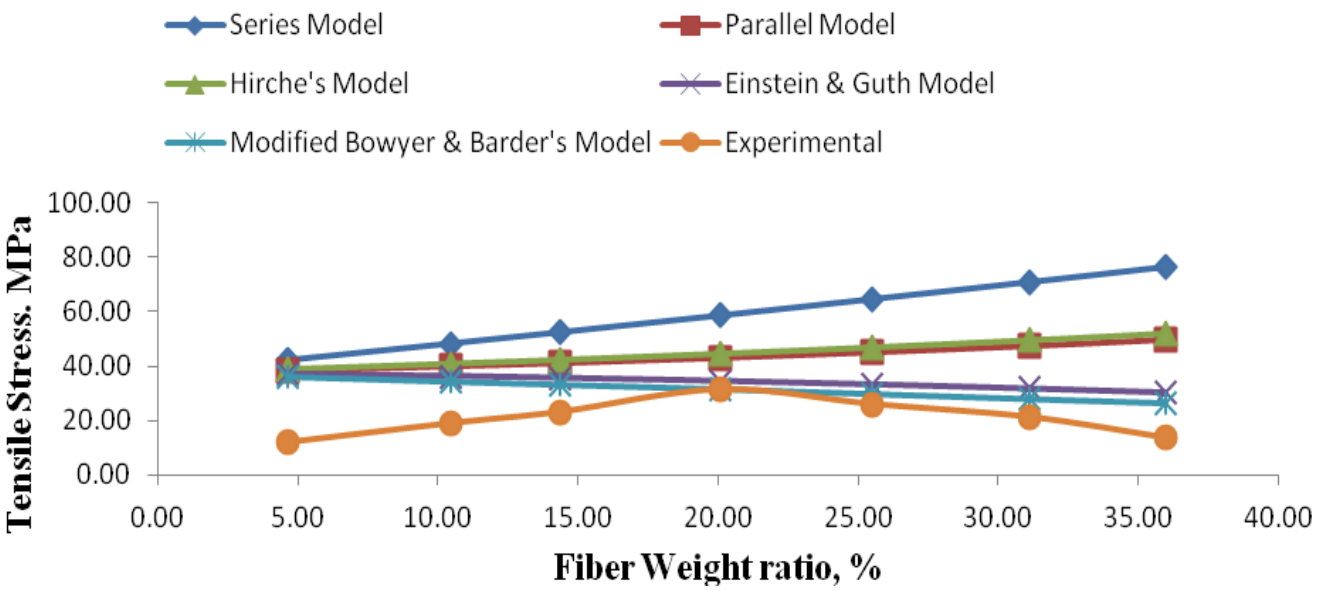

Figure10. Comparison of composite Stress for different models

\section{CONCLUSIONS}

A composite is successfully manufactured from the waste human hair fibers that are abundantly available in the market as a waste human by product.

The effect of fiber volume fraction and fiber length on tensile properties of a random oriented HHRC is investigated.

It is observed that the Maximum tensile strength of the Human Hair Reinforced Composites is $31.45 \mathrm{MPa}$ which occurred at $30 \mathrm{~mm}$ fiber length. Also it is increasing with increase in Fiber length up to 30 $\mathrm{mm}$ and further increase in Fiber length has resulted in decrease in tensile strength. Similar results are observed by Yashwanth S. Munde and et al. ${ }^{5}$, who carried out experimentation on coir Fiber reinforced composites.

Of all the fiber loadings, maximum tensile strength is recorded at $20 \%$ fiber weight ratio. It is increasing with increase in Fiber weight ratio up to $20 \%$, further increase in fiber weight ratio has resulted in decreased tensile strength of the composite. This tendency is observed at all Fiber lengths. Similar types of results are published by T. Subramani et al..$^{20}$, in 
their investigation on chicken feather reinforced composites.

Maximum Tensile modulus value of $4.13 \mathrm{GPa}$ is observed at $20 \%$ fiber loading.

Tensile Stress and Modulus are estimated using different theoretical models and are compared with the experimental values. Experimental values are found to be in close agreement with theoretical models.

\section{REFERENCES}

1. Dieter H. Mueller and Andreas Krobjilowski, New Discovery in the Properties of Composites Reinforced with Natural Fibers, Journal of Industrial Textiles, Vol. No.33, Issue No. 2, (2003), PP No.111-130.

2. M. Uzun, E. Sancak, I. Patel, I. Usta, M. Akalın, M. Yuksek, Mechanical behaviour of chicken quills and chicken feather Fibers reinforced polymeric composites, Archives of Materials Science and Engineering, Vol.No. 52, Issue. No. 2, (2011), PP No. 82-86.

3. Jolon Dyer and Anita Grosvenor, Protein Fiber Surface Modification, Natural Dyes, Dr. Emriye Akcakoca Kumbasar (Ed.), ISBN: 978-953-307783-3, In Tech, 2011.

4. C. R. Robbins, Chemical and Physical Behaviour of Human Hair, 5th Edition, Springer-Verlag Berlin Heidelberg, New York, 2012.

5. Yashwant S. Munde and Ravindra B. Ingle, Theoretical modelling and experimental verification of Mechanical Properties of Natural Fiber Reinforced Thermoplastics, Procedia Technology, Vol. No.19, (2015) PP No. 320 - 326.

6. Ankush Gupta, "Human Hair "Waste" and Its Utilization: Gaps and Possibilities," Journal of Waste Management, Vol.No. 2014, (2014) PP No. 1-17.

7. Fuchs E. Keratins and the skin. Annu Rev Cell Dev Biol. 1995; 11:123-53.

8. $\mathrm{Yu}$ J, Yu DW, Checkla DM, Freedberg IM, Bertolino AP. Human hair keratins. J Invest Dermatol. 1993 Jul;101(1 Suppl):56S-59S.

9. Wei G, Bhushan B, Torgerson PM (2005) Nanomechanicalcharacterization of human hair using Nano-indentation and SEM.Ultramicroscopy 105: 248-266.

10. Zhenxing $\mathrm{Hu}$; Gaosheng $\mathrm{Li}$; Huimin Xie ; Tao Hua ; Pengwan Chen, et al."Measurement of Young's modulus and Poisson's ratio of human hair using optical techniques", Proc. SPIE 7522, Fourth International Conference on Experimental Mechanics, 75222Q (April 14, 2010);
11. Harjeet S.Jaggi, Yogesh Kumar, Bhabani K.Satapathy. Analytical interpretations of structural and mechanical responses of high density polyethylenehydroxyapatite biocomposites. Materials and Design 2012; 36:757766

12. G. Kalaprasad, K.Joseph, S.Thomas. Theoritical modelling of tensile properties of short sisal fiber reinforced low -density polyethylene composites. Journal of Materials science 1997; 32:4261-4267

13. Anshid, A., Haneef, A., Panampilly Bindu, Indose Aravind and Sabu Thomas(2008) Studies on tensile and flexural properties of short banana/glass hybrid fiber reinforced polystyrene composites. Journal of Composite Materials,42(15).

14. Harris B. Engineering composite materials. London: The Institute of Materials; 1999.

15. Ghosh R, Reena G, Krishna AR, Raju BHL. Effect of fibre volume fraction on the tensile strength of Banana fibre reinforced vinyl ester resin composites. Int JAdv Eng Sci Technol 2011;4(1):89-91.

16. Madsen B, Thygesen A, Liholt H. Plant fibre composites - porosity and stiffness.Compos Sci Technol 2009;69:1057-69.

17. Madsen B, Hoffmeyer P, Lilholt H. Hemp yarn reinforced composites - II.Tensile properties. Compos Part A: Appl Sci Manuf 2007;38:220415.

18. Pan N. Theoretical determination of the optimal fiber volume fraction andfibre-matrix property compatibility of short fiber composites. Polym Compos1993;14(2):85-93.

19. Shah DU, Schubel PJ, Licence P, Clifford MJ. "Determining the minimum, critical and maximum fibre content for twisted yarn reinforced plant fibre composites", Composites Science and Technology (2012). 72: p. 1909-1917 DOI: 10.1016/j.compscitech.2012.08.005

20. T. Subramani, Krishna, S., Ganesan,, S.K., Nagarajan, G., International Journal of Research and Applications, Vol. No. 4, Issue No. 12( Part 4), (2014), PP No.93-104. 